RUA, M.A.S. et al. Espermatogênese em eqüinos. PUBVET, Londrina, V. 8, N. 7, Ed. 256, Art. 1696, Abril, 2014.

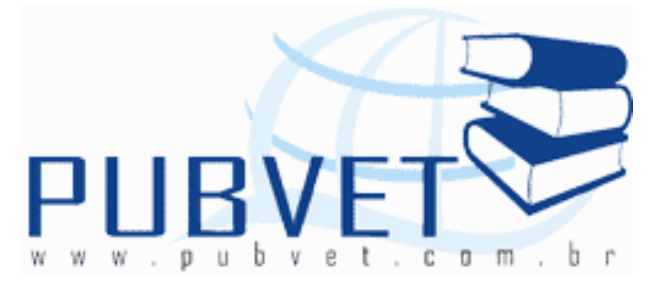

PUBVET, Publicações em Medicina Veterinária e Zootecnia.

\title{
Espermatogênese em eqüinos
}

Miguel Alejandro Silva Rua ${ }^{3}$, Celia Raquel Quirino ${ }^{1}$, Aline Pacheco ${ }^{2}$, Mariana da Silva Ribeiro ${ }^{4}$, Aylton Bartholazzi Junior ${ }^{3}$, Wilder Hernando O. Vega ${ }^{3}$

${ }^{1}$ Professora do Laboratório de reprodução e melhoramento genético animal da Universidade Estadual do Norte Fluminense/UENF ${ }^{2}$ Bolsista Pós doutorado CAPES/FAPERJ

${ }^{3}$ Alunos de Pós graduação do Laboratório de reprodução e melhoramento genético animal da Universidade Estadual do Norte Fluminense/UENF ${ }^{4}$ Alunos de graduação da Universidade Estadual do Norte Fluminense/UENF ${ }^{5}$ Bolsista Extensão da Universidade Estadual do Norte Fluminense/UENF Autor: miquelvet-rua@hotmail.com.

\section{Resumo}

O objetivo do presente trabalho foi discutir os aspectos ligados a espermatogênese, suas fazes, e fatores que podem influenciar em sua ocorrência. A espermatogênese é um processo de divisão e diferenciação celular em que são produzidos espermatozóides no interior do testículo. A eficiência da espermatogênese nos garanhões é influenciada por diferenças entre espécies, número de células germinativas e fatores ambientais. A atividade das espermatogônias e espermátides divide a espermatogênese em fazes que são a espermatocitogênese, meiose e diferenciação e espermiogênese respectivamente. A sazonalidade também influencia no 
RUA, M.A.S. et al. Espermatogênese em eqüinos. PUBVET, Londrina, V. 8, N. 7, Ed. 256, Art. 1696, Abril, 2014.

desenvolvimento da espermatogênese podendo ocorrer maior degeneração de células germinativas fora da estação de monta. O objetivo do presente trabalho foi discutir os aspectos ligados a espermatogênese, suas fazes, e fatores que podem influenciar em sua ocorrência. São necessários mais estudos para entender o processo da espermatogênese em equinos situados no território brasileiro, com as condições climáticas nas quais são submetidos.

\section{Spermatogenesis in horses}

\section{Abstract}

The aim of this study was discuss about the aspects of spermatogenesis, and the facts that may influence its occurrence. Spermatogenesis is the process of cell division and cell differentiation by with spermatozoa are produced in testes. Efficiency of spermatogenesis in stallions is influenced by species differences and numerical density of germ cell. Activities of spermatogonia, spermatocytes and spermatids partition spermatogenesis into phases that are the spermatocitogenesis, meiosis, differentiation and spermiogenesis, respectively. Seasonality influences on the developmental in spermatogenesis that can occur more germ cell degeneration out of the breed season. The aim of this study was discuss about the aspects of spermatogenesis, and the facts that may influence its occurrence. More studies are needed to understand the process of spermatogenesis in horses located in Brazil territory, with climate conditions that are submitted.

\section{Introdução}

A espermatogênese é um processo que ocorre no parênquima testicular em que consiste em um conjunto de divisões e diferenciações celulares a partir de uma célula primordial denominada espermatogônia resultando na produção de espermatozóides (Amann, 1993b; Garner \& Hafez, 2004).

A espermatogênese começa a ocorrer próximo à puberdade e normalmente, este processo continua por toda vida do garanhão (Setchei, 
RUA, M.A.S. et al. Espermatogênese em eqüinos. PUBVET, Londrina, V. 8, N. 7, Ed. 256, Art. 1696, Abril, 2014.

1982). Porém, podem-se observar consideráveis variações nas características seminais e no comportamento sexual do garanhão de acordo com a idade e sazonalidade (Pickett. 1993).

Foi estabelecido que nas espécies de mamíferos, incluindo os equinos, normalmente a espermatogênese depende de uma perfeita interação do eixo hipotalâmico-hipofisário-gonadal, o qual envolve ação endócrina de gonadotrofinas, mecanismos de feedback de esteróides e proteínas, assim como modulação paracrino/autócrina (Genessi et al., 1997). O controle endócrino envolve mudanças nos padrões de secreção do hormônio hipotalâmico, o hormônio liberador de gonadotrofina (GnRH), e hormônios da pituitária anterior, hormônio luteinizante (LH) e hormônio folículo estimulante (FSH), também hormônios testiculares como os andrógenos e inibina (Amann, 1993a; Weinbauer and Nieshlag, 1993).

O sistema parácrino/autócrino tem o papel de coordenar varias funções em diferentes células testiculares (Genessi et al., 1997).

O objetivo do presente trabalho foi discutir os aspectos ligados a espermatogênese, suas fazes, e fatores que podem influenciar em sua ocorrência.

\section{Espermatogênese}

A espermatogênese ocorre dentro dos túbulos seminíferos e consiste na transformação e desenvolvimento de células germinativas.

Está subdividida em três fases. A primeira, designada fase de proliferação ou espermatocitogênese, que consiste em todas as divisões mitóticas das espermatogônias. Existem várias gerações de espermatogônias e cada uma sofre divisão mitótica, gerando um grande número de espermatogônia do tipo B. Algumas espermatogônias voltam a um estágio mais primitivo, promovem assim uma contínua substituição (renovação) do sistema de células a partir de uma nova espermatogônia (SENGER, 2003).

A segunda fase da espermatogênese é denominada de meiótica. Esta fase envolve espermatócitos primários e secundários. Durante a fase meiótica 
RUA, M.A.S. et al. Espermatogênese em eqüinos. PUBVET, Londrina, V. 8, N. 7, Ed. 256, Art. 1696, Abril, 2014.

a diversidade genética é garantida pela replicação do DNA e pelo crossing over, produzindo espermátides haplóides (n) (SENGER, 2003).

A terceira fase da espermatogênese é a fase de diferenciação, denominada de "espermiogênese". . Durante a fase de diferenciação, não ocorre mais divisão celular, a espermátide indiferenciada e arredondada passa por uma serie de transformações que resulta na produção de uma célula altamente diferenciada que é o espermatozóide; contendo uma cabeça (material nuclear), um flagelo incluindo a peça intermédia (com hélice mitocondrial) e uma peça principal (SENGER, 2003).

O estabelecimento da espermatogênese na maioria das espécies ocorre aleatoriamente em todo o testículo (COURT et al., 1970). Em análise histológica realizada em cavalos com menos de dois anos de idade, pode-se observar o parênquima testicular mais claro no centro e parênquima mais escuro na periferia (JOHNSON, 1991b). A uniformidade no parênquima testicular mais claro é associada com a realização da espermatogênese nos testículos desses cavalos, enquanto as partes mais escuras do parênquima é associado com mudanças na população das células testiculares (NISHIKAWA e HORIE, 1955; JOHNSON, 1981).

\section{Proliferação celular ou espermatocitogênese}

A célula mais primitiva encontrada no epitélio do túbulo seminífero é a espermatogônia. Essas células diplóides (2n) especializadas são localizadas no compartimento basal do epitélio seminífero. Existem três tipos de espermatogônias: espermatogônia - A, espermatogônia - I e espermatogônia B. A espermatogônia - A sofre várias divisões mitóticas, as quais progridem mitoticamente da $A_{1}$ até $A_{4}$, com isso um pool de células tronco é mantido, Essas células tronco dividem-se mitoticamente para promover uma contínua fonte de espermatogônia - A, possibilitando a continuação da espermatogênese sem interrupções por anos (SENGER, 2003).

Em equinos a espermatocitogênese tem duração de aproximadamente 19,4 dias (AMMAN, 1993b). 
RUA, M.A.S. et al. Espermatogênese em eqüinos. PUBVET, Londrina, V. 8, N. 7, Ed. 256, Art. 1696, Abril, 2014.

\section{Segunda fase (meiose)}

Durante a espermatogênese, o número de cromossomos é reduzido, através da meiose, tornando-se a célula germinativa haplóide. As divisões mitóticas da espermatogônia - B, resultam na formação de espermatócitos primário (SENGER, 2003), os quais imediatamente entram em sua primeira prófase meiótica e se dividem para formação de espermatócitos secundários. Posteriormente, há a divisão para a forma de espermátide arredondada. Estas duas divisões resultam na conversão do complemento cromossômico diplóide a haplóide, e células passam da longa fase de primeira divisão meiótica que pode ser subdividia em bases citológicas nas fases proleptóteno, leptóteno, zigóteno, paquíteno e diplóteno (KRESTER et al., 1998). Cada um desses estágios representa um diferente passo na progressão da síntese e replicação de DNA (SENGER, 2003).

$\mathrm{Na}$ fase de proleptóteno, ocorre a completa replicação do DNA. Essas tétrades então se fundem em um ponto aleatório conhecido como crossingover do DNA. O crossing-over resulta em aleatórios segmentos de cada cromossomo. Com isso, a prófase da primeira divisão meiótica garante a existência da heterogeneidade e que cada espermatócito secundário e espermátide será geneticamente única (SENGER, 2003).

Maekawa et al. (1989) relataram uma proteína cognata (HSC-70), que tem uma forma expressiva nos testículos, na pós-meiose das espermátides.

Dix et al. (1996) demonstraram que a heat-shock protein 70-2 (HSP-702), um único membro do grupo de proteínas HSP-70, é essencial para a realização da meiose. A HSP-70-2 é expressa em altas concentrações na fase de paquíteno do espermatócito.

Em animais geneticamente modificados, dos quais o gene de expressão da HSP-70-2 é deletada, há uma falha em completar a meiose nas células germinativas, assim como há um aumento marcante na apoptose de espermatócitos. Outros dados sugerem que a HSP-70-2 é um importante componente do complexo synaptoneal, o qual é um elemento crucial no 
RUA, M.A.S. et al. Espermatogênese em eqüinos. PUBVET, Londrina, V. 8, N. 7, Ed. 256, Art. 1696, Abril, 2014.

pareamento de cromossomos homólogos durante a prófase da meiose (ALLEN et al., 1996).

Byskov et al. (1995) identificaram uma série de esteróides isolados de estratos de testículos bovinos e de fluidos foliculares de humano que induzem meiose em células do cúmulos de oócitos. O esteróide ativador da meiose encontrado provindo dos testículos é o 4,4-dimethyl-5a-cholest-8,24-diene-3ßol e a $\mathrm{C}_{29}$ esterol, também denominada 4,4-dimethyl-zymosterol.

Outra marcante mudança citologia que ocorre nas células durante a meiose, é a mudança na morfologia mitocondrial. A típica mitocôndria com cristas dispostas transversalmente e é transformada seguindo uma inicial dilatação de espaços intercristas de mitocôndrias de espermatócitos primários e, posteriormente, as células germinativas assumem o formato vacuolizado (SENGER, 2003). O mesmo autor reportou que essas mudanças na morfologia mitocondrial são dependentes de proteínas secretadas pelas células de Sertoli.

Essa fase tem duração de cerca de 19,4 dias nos equinos (AMMAN, 1993b).

\section{Terceira fase (diferenciação espermática)}

O papel do espermatozóide é transportar o material genético masculino até o oócito durante a fertilização. No entanto, para a formação de células capazes de realizar a fertilização, espermátides esféricas sofrem uma série de mudanças, as quais o núcleo se torna mais condensado, ocorre a formação do acrossoma e a célula se torna potencialmente móvel (SENGER, 2003).

As espermátides arredondadas, as quais são decorrentes da segunda divisão meiótica, sofrem uma série de complexos eventos que as transformam em espermatozóides (KRESTER and KERR, 1994). Esse processo consiste:

(I) Condensação nuclear e movimento do núcleo para a periferia das células;

(II)Formação de um lisossomo modificado, conhecido como acrossomo, o qual se prende a superfície do núcleo em justaposição com a membrana celular; 
RUA, M.A.S. et al. Espermatogênese em eqüinos. PUBVET, Londrina, V. 8, N. 7, Ed. 256, Art. 1696, Abril, 2014.

(III) Formação do flagelo em que inclui o desenvolvimento de um núcleo de microtúbulos, o axonema, que surgem dos centríolos de espermátides arredondadas.

Inicialmente na formação do axonema, uma série de microtúbulos (em dupla) igualmente espaçados, circundam dois microtúbulos (individuais) centrais, no citoplasma adjacente ao complexo de Golgi, posteriormente na espermatogênese, essas estruturas estão localizadas no pólo abacrossomal do núcleo através de uma articulação complexa formando o colo do espermatozóide.

Posteriormente, na formação da cauda, o axonema é modificado pelo desenvolvimento de uma séria de nove fibras elétron densas, denominadas de fibra densa exterior, na região da peça intermediária do espermatozóide distal pela formação da bainha fibrosa na região da peça principal;

(IV) Finalmente, seguindo a realização desses eventos, a espermátide possui um grande compartimento com citoplasma residual, o qual é fagocitado pelas células de Sertoli.

\section{Formação do acrossoma}

A espermátide mais recentemente formada contém um Complexo de Golgi grande, e altamente desenvolvido localizado próximo do núcleo que consiste em pequenas vesículas. Em uma espermátide o complexo de Golgi dará origem a uma importante organela subcelular conhecida como acrossomo. Primeiramente, vesículas são formadas, gerando uma grande vesícula localizada ao lado do núcleo. Essa vesícula é chamada de vesícula acrossômica e contém um denso acrossomo granulado. Pequenas vesículas de Golgi são continuamente adicionadas à vesícula maior, aumentando assim seu tamanho (SENGER, 2003).

Outro evento que ocorre na espermiogênese é a formação da cauda. Enquanto a vesícula acrossômica esta sendo formada, os centríolos migram para o citoplasma em direção à base do núcleo. O centríolo proximal dará origem a um aparato de implantação que permite o flagelo ser ancorado ao 
RUA, M.A.S. et al. Espermatogênese em eqüinos. PUBVET, Londrina, V. 8, N. 7, Ed. 256, Art. 1696, Abril, 2014.

núcleo. O centríolo distal dará origem ao desenvolvimento do axonema. O axonema é a porção central do flagelo, nesse caso, a cauda do espermatozóide (SENGER, 2003).

O axonema é claramente de origem centriolar e a geração da motilidade emerge dos microtúbulos, composto por protofilamentos de tubulina, um heterodimero de a e $\beta$ tubulina e os componentes protéicos completando o axonema, incluindo os raios radiais, ligações nexin e dynein arms(KRETSER and KERR, 1994). Esse último representa uma proteína com atividade ATPase. Defeitos genéticos resultando em falta de dyneinarms são associados com a síndrome da imobilidade ciliar (ELIASSON et al., 1977). Alem disso, anormalidades como a ausência de nexin linkages ou radial spokes, podem também resultar em imobilidade ciliar, indicando um papel crucial dessas proteínas no controle da mobilidade (AFZELIUS and ELIASSON, 1979).

Há um aumento na compreensão do número de genes que são expressos pelo genoma haplóide envolvidos na espermatogênese. Os genes que codificam protaminas, e as proteínas que substituem as histonas ligadas ao DNA, tem sido estudados. Esses genes tem sido importantes uma vez que, como vários outros genes expressos em células haplóides, eles são transcritos no início da espermatogênese e o RNA resultante é armazenado até o final desse processo para tradução da proteína (HECHT, 1996).

Hecht (1996) estudou o mecanismo em que o mRNA permanece estável por aproximadamente sete dias nas células haplóides. Uma proteína de ligação ao RNA foi identificada nos testículos, e podem estar envolvidas na manutenção da estabilidade desses mRNAs através do reconhecimento de uma sequência específica de nucleotídeos.

A presença e expressão gênica de várias proteínas específicas são imprescindíveis em cada uma das fases da espermatogênese. Dentre as proteínas de extrema importância encontram-se as histonas e protaminas que atuam na fase final da espermatogênese. As histonas contidas nas espermátides de forma redonda são substituídas por protaminas, proteínas 
RUA, M.A.S. et al. Espermatogênese em eqüinos. PUBVET, Londrina, V. 8, N. 7, Ed. 256, Art. 1696, Abril, 2014.

nucleares, cujo papel é reorganizar o DNA constituindo uma estrutura altamente condensada (WARD et al., 1999).

A cromatina nuclear é definitivamente condensada durante o trânsito pelo epidídimo. Nesta etapa há alteração na estrutura nuclear por fatores mecânicos e químicos, aumentando a habilidade de fecundação e de manter o desenvolvimento embrionário. Portanto, tanto os eventos da espermatogênese quanto a maturação pós-testicular são necessários para competência das células espermáticas (FRANCAVILLA et al., 1996).

Existem proteínas específicas para cada fase da espermatogênese, e existem genes cuja expressão é imprescindível durante a espermiogênese. Essa expressão dos genes durante a espermiogênese dá-se ao nível de transição e é medida por vários fatores, como à proteína basonuclina, e a proteína STAT (signal transducer and activation of transcription). À medida que o processo da espermiogênese avança, toda vez que alguma proteína for necessária à continuação deste processo, a transcrição cessa e o mRNA tornase ativo para sintetizar as respectivas proteínas, como acontece, por exemplo, na síntese das proteínas e proteínas de transcrição (MAHONEY et al., 1998).

Finalmente ocorre a liberação do espermatozóide pelas células de Sertoli para o interior do túbulo seminífero. Essa liberação é denominada espermiação, que é considerada análoga a ovulação na fêmea, exceto pelo fato da espermiação ocorrer continuamente ao longo de todo o testículo (SENGER, 2003) e durante toda a vida reprodutiva do animal (GARNER \& HAFEZ, 2004).

Entender o mecanismo responsável pela contínua produção de espermatozóides pelo epitélio seminífero representa um dos maiores desafios em pesquisas sobre a fisiologia reprodutiva (SENGER, 2003; GARNER \& HAFEZ, 2004)

A partir da perspectiva clínica, a avaliação do número de espermatozóides por ejaculado não reflete com acurácia uma anormalidade na espermatogênese. Com isso podem haver erros na avaliação dos macho acarretando assim em más decisões sobre a escolha ou descarte de animais da reprodução. (GARNER \& HAFEZ, 2004) 
RUA, M.A.S. et al. Espermatogênese em eqüinos. PUBVET, Londrina, V. 8, N. 7, Ed. 256, Art. 1696, Abril, 2014.

É necessário entender que há um período de 2 a 4 semana para que sejam observados efeitos deletérios no sêmen após o animal ter sofrido algum tipo de evento como (estresse térmico, viagens, febre, exposição à certas toxinas e alguns medicamentos) (SENGER, 2003).

Além disso, são requeridas de 6 a 12 semanas para restauração da normalidade na espermatogênese. Portanto, interpretações clínicas da característica do ejaculado requer conhecimento específico do tempo da espermatogênese em cada espécie a ser avaliada (SENGER, 2003). Em equinos a espermatogênese dura em torno de 57 dias (AMANN, 1993a).

\section{Ciclo do epitélio do túbulo seminífero}

O ciclo do epitélio seminífero é a progressão de uma completa série de associações celulares (estágios) em um local ao longo do epitélio do túbulo seminífero, sendo único para cada espécie.(SENGER, 2003; GARNER \& HAFEZ, 2004)

Ao observar em um microscópio óptico um corte transversal no túbulo seminífero, pode-se observar de quatro a cinco camadas concêntricas de células germinativas. As células de cada camada se desenvolvem em sincronismo e em grupos. Cada geração de células (cada camada concêntrica) tem uma similar aparência e função. Cortes transversais ao longo do comprimento do túbulo seminífero terá diferentes aparências.(SENGER, 2003; GARNER \& HAFEZ, 2004)

Cada geração de células germinativas dará origem a uma geração sucessiva, uma geração mais avançada. (SENGER, 2003; GARNER \& HAFEZ, 2004)

O Estágio I consiste em uma geração de espermatogônia do tipo A localizadas perto da membrana basal. Logo acima dessa camada de espermatogônia - A, há uma geração de espermatócitos jovens. Acima, se encontra a terceira geração que consiste em espermatócitos mais maduros. Finalmente, perto do lúmen, encontra-se a quarta geração de células. Essa geração consiste em esféricas espermátides imaturas. Contudo, pode-se 
RUA, M.A.S. et al. Espermatogênese em eqüinos. PUBVET, Londrina, V. 8, N. 7, Ed. 256, Art. 1696, Abril, 2014.

observar que quanto mais imaturo o tipo celular, mais perto da membrana basal estão localizados, e quanto mais avançado o tipo celular, mas próximo ao lúmen túbulo seminífero estão localizados (SENGER, 2003).

Cortes transversais em localizações aleatórias no túbulo seminífero apresentam diferentes gerações celulares. As células de cada seção são ativamente engajadas na espermatogênese, porém apenas uma seção é capaz de liberar espermatozóides para o lúmen do túbulo seminífero. Assim, ao longo do comprimento do túbulo seminífero há apenas certas zonas (cortes transversais) em que espermatozóides são liberados a cada segundo. Enquanto isso, todas as demais zonas ou estágios estão preparando para liberar espermatozóides, mas as células nessas zonas não alcançaram o apropriado estágio de maturidade para que ocorra a espermiação (SENGER, 2003; GARNER \& HAFEZ, 2004).

\section{Tempo de espermatogênese}

O tempo em que uma espermatogônia se torna um espermatozóide incorporado dentro do lúmen do túbulo seminífero é de 55 a 57 dias no garanhão. Esse processo de liberação de espermatozóides no lúmen do túbulo seminífero é chamado de espermiação. Em aproximadamente nove dias ocorre o transporte dos espermatozóides através do sistema de ductos epididimários, consequentemente, uma nova população de espermatozóides pode ser ejaculada após 64 a 66 dias aproximadamente (AMANN, 1993, LOVE, 2002).

De acordo com Eddy, (1999), as proteínas HSP70 (Heat-shock proteins) e a HSP70-2, são necessárias no início da meiose, fato importante que poderá esclarecer a eventuais falhas na formação de espermatozóides em animais criados em climas tropicais.

Foi evidenciada em estudos "in vitro" a existência de uma estreita relação entre as células de Sertoli e Leyding mediada por fatores de natureza protéica capaz de influenciar a proliferação e a atividade esteroidogênica das células de Leyding (SHARPE, 1993). Essas proteínas de vários pesos 
RUA, M.A.S. et al. Espermatogênese em eqüinos. PUBVET, Londrina, V. 8, N. 7, Ed. 256, Art. 1696, Abril, 2014.

moleculares atuam sob efeito do FSH e testosterona, e possuem efeitos mitogênicos (PAPADOPOLOS, 1991).

\section{Sazonalidade}

Nos garanhões há uma modulação ou regulação da produção diária de espermatozóides variando durante as estações. No entanto, os machos da espécie equina continuam com a produção de espermatozóides no decorrer de todo o ano. O efeito sazonal na espermatogênese ocorre em função da degeneração celular durante a meiose e a modulação sazonal no número de espermatogônias do tipo $A$, é duas vezes maior na estação de monta do que fora dela (JOHNSON, 1985).

Nos garanhões as diferenças sazonais no número de espermatogônia são maiores que as diferenças sazonais na produção diária de espermatozóides (JOHNSON, 1985).

As diferenças sazonais na produção diária de espermatozóides em cavalos podem ser explicadas por mudanças no número de espermatogônia A, presentes no parênquima testicular do garanhão (JOHNSON, 1985).

Johnson, (1991a) observou que na estação de monta, as médias de peso do parênquima testicular, número de células de Leyding, células de Sertoli e espermátides com núcleo esférico foram maiores do que quando realizada a mesma observação fora da estação de monta (inverno). Os mesmos autores, também observaram que a produção diária de espermatozóides por testículo e por grama de parênquima também foram maiores durante a estação de monta (verão).

Johnson, (1991a) observou que independente da estação, cinco subtipos de espermatogônias foram distinguidas em secções nos túbulos seminíferos. As espermatogônias $A_{1}$ e $A_{2}$ foram encontradas em todos os estágios do ciclo do epitélio do túbulo seminífero. A espermatogônia $A_{3}$ foi encontrada em todos os estágios, porém foram mais prevalentes no estágio I-III. A espermatogônia $B_{1}$ foi encontrada no estágio IV e $V$, e a espermatogônia $B_{2}$ foi encontrada no estágio VI e VII. 
RUA, M.A.S. et al. Espermatogênese em eqüinos. PUBVET, Londrina, V. 8, N. 7, Ed. 256, Art. 1696, Abril, 2014.

O maior número de espermatogônias $A_{2}$ e $A_{3}$ na estação de monta (verão) é decorrente do maior número de espermatogônias $A_{1}$ e $A_{2}$ no início da espermatocitogênese (JOHNSON, 1991a).

De acordo com Johnson (1991a), as diferenças sazonais em determinados subtipos de espermatogônias, revelam significantes diferenças nos rendimentos das divisões espermatogoniais. Johnson et al. (1991c) observaram em seus estudos uma correlação significativa entre produção diária de espermatozóides e número de células de Sertoli por cavalo ( $r=$ $0,80)$, entre produção diária de espermatozóides com peso do parênquima testicular $(r=0,94)$ e entre produção diária de espermatozóide e peso do parênquima testicular $(r=0,85)$. Berndtson e Jones (1989) estudando garanhões de várias idades reportaram correlação significante entre o número relativo de células de Sertoli e o número de populações de células germinativas. Em cavalos adultos (mais de quatro anos de idade) o número de células de Sertoli por testículo teve correlação significativa e positiva com o número de espermátides arredondadas por testículo $(r=0,65)$, espermátide primária em estágios mais avançados $(r=70)$, espermatócitos primário em estágios menos avançados $(0,67)$ e espermatogônias $B_{2}(0,63)$ (JOHNSON e TATUM, 1989).

\section{Conclusão}

A espermatogênese em garanhões envolve o mecanismo endócrino e modulação parácrino/autócrino. Os testículos dos garanhões são controlados pelo sistema endócrino. No entanto, são necessários mais estudos para melhorar o entendimento sobre os fatores de interação celular presente no testículo de equinos. As ações ambientais que possam interferir na espermatogênese em diferentes regiões do Brasil, em condições climáticas diferentes e em raças diferentes, visto que no país há um grande número de criadores, e rebanhos de equinos de diversas raças. 


\section{Bibliografia}

AFZELIUS, B.A. AND ELIASSON, R. Flagellar mutants in man: on the heterogeneity of the immotile ciliasyndrome. J. Ultrastruct. Res., 69, 43-52. 1979.

ALLEN, J.W., DIX, D.J., COLLINS, B.W. et al. HSP-70-2 is part of the synaptonemal complex in mouseand hamster spermatocytes. Chromosoma, 104, 414-421. 1996

AMANN R. P. Spermatogenesis in the stallion: a review. J Equine Vet Sci I:131-39, 1981

AMANN, R.P. Physiology and endocrinology.Equine Reproduction, p.658-673,1993a.

AMANN, R.P. Functional Anatomy of the Adult Male. In: McKKINON, A.O.; VOSS, J.L. Equine Reproduction. $1^{\circ}$ ed, Philadelphia: Lea \&Fabiger, cap. 76, p. 645-657. 1993b

BERNDTSON WE AND JONES LS (1989) Relationship of intratesticular testosteronecontent of stallions to age, spermatogenesis, Sertoli cell distribution andgerm cell-Sertoli cell ratios Journal of Reproduction and Fertility 85 511-518.

BYSKOV, A.G., ANDERSON, C.Y., NORDHOLM, L. Chemical structure of sterols that activateoocyte meiosis. Nature, 374, 559-562. 1995.

BORTOLUSSI, M., ZANCHETTA, R., BELVEDERE, P., COLOMBO, L., 1990.Sertoli and Leydig cell numbers and gonadotropinreceptors in rat testis from birth to puberty. Cell Tissue Res. 260, $185-191$.

CLAY CM, SQUIRES EL, ANTANN RI'. NETT TM, 1988. Influences of season andartificiaplhotoperiodon stallions:luteinizing hormone, follicle-stimulatinghormone and testosterone. J AnimSci 66:1246-55.

COUROT M, HOCHEREAU-DE REVIERS M-T, ORTAVANT R. Spermatogenesis. In: JohnsonAD, Gomes WR, Van Demark NL (eds.), The Testis. vol. I. New York: AcademicPress: 339-442. 1970.

DIX, D.J., ALLEN, J.W, COLLINS, B.W.et al. Targetted gene disruption of HSP70-2 results in failedmeiosis, germ cell apoptosis and male infertility. Proc.Natl. Acad. Sci. USA, 93, 32643268. 1996

DYM, M. O Sistema Reprodutor Masculino. In: Koogan S.A., 1981, p. 824-836.

Histologia. Rio de Janeiro: Guanabara-

ELIASSON, R., MOSSBERG, B., CAMNER, P.et al.The immotile cilia syndrome. A congenital ciliaryabnormality as an etiologic factor in chronic airwayinfections and male sterility. N. Engl. J. Med., 297,1-6. 1977.

EDDY, M. Spermatogenesis and HSP70 chaperones. Biology Reproduction, Madison.V.60, Suppl. 1, p.74, 1999.

EISENHAUER, K.M., ROSER, J.F., 1995. Effects of lipoproteins, eLH, eFSH and ePRL on equine testicularsteroidogenesis in vitro.J. Androl. 16, 18-27.

FRANCAVILLA, S.; CORDESCHI, G.; GABRIELE, A. Et al. Chromatin defects in normal and malformed human ejaculated and epididimal spermatozoa, a cytochemical ultrastrutural study. Journal Reproduction Fertility., v.106, p.259 268, 1996. 
GARNER, D.L., HAFEZ, E.S.E. Espermatozóide e plasma seminal. In: Reprodução Animal HAFEZ, E.S.E., HAFEZ, B. $7^{\text {a }}$ ed.Cap.7 p. 97-107. 2004

GNESSI, L., FABBRI, A., SPERA, G., 1997. Gonadal peptides as mediators of development and functional control of

GRISWOLD, M.D. Interactions between Germ Cells and Sertoli Cells in the Testis.Biology of Reproduction, vol. 52, p. 211-216, 1995.the testis: an integrated system with hormones and local environment. Endocrine Rev. 18, 541-609.

HECHT, W.B. Post transcriptional regulation ofpost meiotic gene expression. In Hansson, V., Levy,F.O. and Tasken, K. (eds), Signal Transduction inTesticular Cells. Springer Verlag, Berlin, pp. 123-140. 1996

HUHTANIEMI, H., TOPPARI, J., 1995. Endocrine, paracrine and autocrine regulation of testicular steroidogenesis. In:

MUKHOPADHYAY, A.K., RAIZADA, M.K. (Eds.), Tissue Renin-Angiotensin Systems. Plenum Press, New York,pp. 33-54.

GARNER, D.L.; HAFEZ, E.S.E.Spermatozoa and Seminal Plasma. In: HAFEZ, E.S.E. Reproduction in Farm Animals. $6^{\text {th }}$ Ed, Philadelphia: Lea \&Fabiger, 2004, cap.7,p165-187.

GNESSI, L., Fabbri, A., Spera, G. Gonadal peptides as mediators of development and functional control of. 1997

the testis: an integrated system with hormones and local environment. Endocrine Rev. 18, 541-609.

IRVINE, C.H.G., ALEXANDER, S.L., 1987. A novel technique for measuring hypothalamic and pituitary hormonesecretion rates from collection of pituitary venous effluent in the normal horse. J. Endocrinol. 113, 183-192.

JEGOU, B.; De GAC, F.; IRBY, D.C. et al. Studies on somniferous tubule fluid production in the adult rat, effect of hypophysectomy and treatment with $\mathrm{FSH}$, $\mathrm{LH}$ and testosterone. Int. Journal of Andrology., v.6, p.249-260, 1983.

JOHNSON L, NEAVES WB. Age-related changes in the Leydig cell population, seminiferoustubules, and sperm production in stallions. BiolReprod; 24:703-712. 1981

JOHNSON L. AND TATUM M.E. Temporal appearance of seasonal changes in numbers of Sertoli cells, Leydig cells, and germ cells in stallions Biology of

Reproduction 40 994-999. 1989

JOHNSON L. Increase daily sperm production in the breeding season of stallions is explained by an elevated population of spermatogonia. BiolReprod; 32:1181-1190. 1985

JOHNSON L. Seasonal differences in equine spermatocytogenesis. Biology of Reproduction 44, 284-291 1991a.

JOHNSON L. SPERMATOGENESIS. In: Cupps PT (ed.), Reproduction in Domestic Animals.4th ed. New York: Academic Press: 173-219. 1991b

JOHNSON, A.L., VARNER, D.D., THOMPSON, D.L.,. Effect of age and season on the establishment of spermatogenesisin the horse. J. Reprod. Fertil. (Suppl. 44), 87-97. 1991c 
JOHNSON L, THOMPSON DL JR. Age-related and seasonal variation in theSertoli cell population, dailysperm production and serum concentrationof follicle-stimulating hormone, luteinizing hormone and testosterone installions.BiolReprod29:777-89. 1983.

JOHNSON L, VARNER DD AND THOMPSON DL, JR (1991) Effect of age and season onthe establishment of spermatogenesis in the horse Journal of Reproduction andFertility 44 87-97

KRETSER, D.M. AND KERR, J.B. The cytology ofthe testis. In Knobil, E. and Neill, J.D. (eds),Physiology \& Reproduction. Raven Press, New York,pp. 1177-1290. 1994

KRETSER, D.M., Loveland, K.L., Meinhardt A., Simorangkir, D., Wreford, N.Spermatigênesis. Human Reproduction Volume 13 Supplement 1. 1998

LOVE, C. Stallion semen evaluation and interpretation.Proceedings Society for Theriogenology, p.93-102, 2002.

MAEKAWA, M., O'BRIEN, D.A., ALLEN, R.L. et al. Heat shock cognate protein (hsc 71) and relatedproteins in mouse spermatogenic cells. Biol. Reprod.,40, 843-852. 1989.

MAHONEY, M.G.; TANG, W.; XING, M.M. et al. Translocation of the zinc finger protein basonuclin from the mouse germ cell nucleus to the midpiece of the spermatozoon during spermiogenesis. Biology Reproduction, v.59, p.388-394,

1998.

MUYAN, M., ROSER, J.F., DYBDAL, N., BALDWIN, D.M., 1993. Modulation of gonadotropinreleasing hormonestimulatedluteinizing hormone release in cultured male equine anterior pituitary cells by gonadal steroids. Biol. Reprod. 49, 340-345.

NADEN, J., AMANN, R.P., SQUIRES, E.L., 1990. Testicular growth, hormone concentrations, seminal characteristics andsexual behaviour in stallions. J. Reprod. Fertil. 88, 167-176.

NISHIKAWA Y, HORIE T. Studies on the development of the testes and epididymides of the horse. I. Studies on the development of the testes of the horse, with specialreference to singularity and the age of sexual maturity. NatlInstAgricSciJpnBull Ser G AnimHusb; 10:229349. 1955.

PAPADOPOULOS, V. Identification and purification of a human Sertoli cell-secreted protein (hSCSP-80) stimulating Leydig cell steroid biosynthesis. Journal Clinic Endocrinology Metabolic, v.72, p.1332-1339, 1991.

PICKETT, B.W. Factors Affecting Sperm Production and Output. In: McKKINON, A.O.; VOSS, J.L. Equine Reproduction. $1^{\circ}$ ed, Philadelphia: Lea \& Fabiger, cap. 78, p. 689-704. 1993

PLANT, T.M., 1986.Gonadal regulation of hypothalamic gonadotropin-releasing hormone release in primates.Endocrine Rev. 7, 75-88.

SENGER, P.L. Pathways to pregnancy and parturition. $2^{\circ}$ Ed.STOUT, T.A.,. Modulating reproductive activity in stallions: a review.Anim. Reprod. Sci. 89, 93-103. 2003.

SHARPE, R.M. Experimental evidence for Sertoli-germ cell and Sertoli-Leydig cell interaction. In: RUSSELL, D.; GRISWOLD, M.D. The Sertoli Cell. Clearwater: Cache River, 1993, p.391418. 
TILBROOK, A.J., DE KRETSER, D.M., Cummins, J.T., Clarke, I.J., 1991. The negative feedback effects of testicularsteroids are predominantly at the hypothalamus in the ram. Endocrinology $129,3080-3092$.

THOMPSON JR., D.L., HONEY, P.G., 1984. Active immunization of prepubertal colts against estrogens: hormonal and testicularresponses after puberty. J. Anim. Sci. 59, 189-196.

TRIBLEY, W.; KIM, J.S.; GRISWOLD, M. FSH-induced down-regulation of the FSHRgene in Sertoli cells involves repressive chromatin structure. BiologicReproduction, v.60, Suppl.1, p.94, 1999.

WARD, W.S.; MCCARTHY, S.; KLAUS, A. et al. The fuction of higher order sperm chromatin structures. Biologic Reproduction, v.60, Suppl.1, p.84, 1999.

ROBERTS KP, ZIRKIN BR. Androgen regulation of spermatogenesis in the rat. Ann NYAcadSci 1991;637:90-106.

RUSSEL, L.D. et al.Mammalian Spermatogenesis. In: _ Histological and Histopathological Evaluation of the Testis. $1^{\circ} \mathrm{ed}$, Bolesta: Cache River Press, 1990, cap.1, p.1-40.

RUSSEL, L. The Mammalian Sertoli Cell and Its Role in Spermatogenesis.XI CONGRESSO BRASILEIRO DE REPRODUÇÃO ANIMAL, 11, 1995, Belo Horizonte. anais - II Congresso Brasileiro de Reprodução Animal - Belo Horizonte: Colégio Brasileiro de Reprodução Animal, 1995, p. 1-6.

SANTOS, J.A. Aparelho Reprodutor Masculino. In __ Patologia Especial dos Mamíferos Domésticos. Rio de Janeiro: Guanabara, 1986, p. 81-106.

SETCHEL, B.P. Spermatogenesis and Spermatozoa In: AUSTIN, C.R.; SHORT, R.V. Reproduction in Mammals. $2^{\circ}$ ed.,Cambridge: Cambridge University Press, vol. 1, cap. 4, pag 63-101. 1982

SYLVESTER, S.R. Leydig cell-Sertoli cell interaction. In: PAYNE, A.H.; HARDY, M.P.; RUSSEL, L.D.The Leydig cell. Vienna: Cache River, 1996, p.467-475.

THOMPSON DL JR. JOHNSON L, ST. GEORGE RI, GARZA F JR, 1986. Concentrations ofprolactin, luteinizinghormone and follicle stimulating hormone in pituitalyand serum of horses: effect of sex, season and reproductive state. JAnimSci63:854-60

THOMPSON JR., D.L., HONEY, P.G., 1984. Active immunization of prepubertal colt against estrogens: hormonal andtesticular responses after puberty. J. Anim. Sci. 59, 189-196.

WEINBAUER GF, NIESCHLAG E. Hormonal control of spermatogenesis. In: de Kretser D(ed), Molecular Biology of Male Reproductive System. New York, Academic Press;99-142. 1993. 